\title{
A case of eruption guidance for eruption disturbances of the bilateral second molars caused by supernumerary teeth
}

\author{
Futabako Iizawa, Kuniko Nakakura-Ohshima, Natsuko Numa and Tadashi Noda \\ Division of Pediatric Dentistry, Department of Oral Health Science, Course for Oral Life Science, \\ Niigata University Graduate School of Medical and Dental Sciences \\ 2-5274 Gakkocho-dori, Niigata 951-8514, JAPAN
}

\begin{abstract}
We report a rare case of eruption disturbance of the bilateral second molars caused by supernumerary teeth in a 7-year-old Japanese boy. The supernumerary teeth were detected by radiographic examination. Computed tomography (CT) was used to examine the positional relationship of the supernumerary teeth and neighboring second molars. CT images showed conical-shaped supernumerary teeth on the upper buccal side of the unerupted mandibular second molars. The cusps of the supernumerary teeth pointed toward the lingual side. Because the two supernumerary teeth threatened to disturb the eruption of the second molars, they were surgically removed at 2 years and 4 months after diagnosis. After removal of the supernumerary teeth, the mandibular second molars erupted at a normal age and aligned normally within the dentition. To the best of our knowledge, this is only one case report of eruption guidance for eruption disturbances of the bilateral second molars caused by supernumerary teeth.
\end{abstract}

\author{
Key words \\ Computed tomography, \\ Eruption disturbance, \\ Eruption guidance, \\ Molar, \\ Supernumerary teeth
}

\section{Introduction}

Eruption disturbances in the mandibular second molar in children constitute $3.2 \%$ of the eruption disturbances in Japanese children, as reported by Noda et al. ${ }^{1)}$ The types of eruption disturbances in the mandibular second molar included delayed eruption (3 cases), abnormal direction and/or position (11 cases), ectopic eruption (7 cases), and cyst formation (2 cases), with no cases of eruption disturbance caused by the supernumerary tooth.

Supernumerary teeth are common and may occur in almost any dentition region. The prevalence of supernumerary teeth is between $0.1-3.8 \%$ in various populations ${ }^{2-8)}$. The upper incisor region is the most common location in which supernumerary teeth appear. Stafne ${ }^{3)}$ reported that approximately $90 \%$ of all supernumerary teeth in his study occurred in the maxilla and that half of these were found in

Received on October 5, 2006

Accepted on February 6, 2007 the incisor regions. He also reported that those in the molar region accounted for $39.8 \%$ of the supernumerary teeth he observed, but that mandibular supernumerary molars were rare, accounting for only $2 \%$ of his sample ${ }^{3)}$. Although several cases of mandibular supernumerary molars have been previously reported, most were located in the distal end of dentition, in the area of the "fourth molars" or "distomolars" ".

In children, supernumerary teeth in the molar region are extremely uncommon. Luten ${ }^{7)}$ reported 32 children with 36 supernumerary teeth $(2 \%)$ on radiographic examination of 1,558 children between the ages of 1 to 9 , and found no supernumerary teeth in the molar region. Rajab and Hamdan ${ }^{10)}$ examined 152 children aged 5 to 15 , finding 202 supernumerary teeth, $90.6 \%$ of which were detected in the incisor region; they reported only one supernumerary molar in the maxilla. To our knowledge, only one case of mandibular supernumerary molars in a young patient has been previously reported ${ }^{11)}$.

Supernumerary teeth may be single or multiple, 


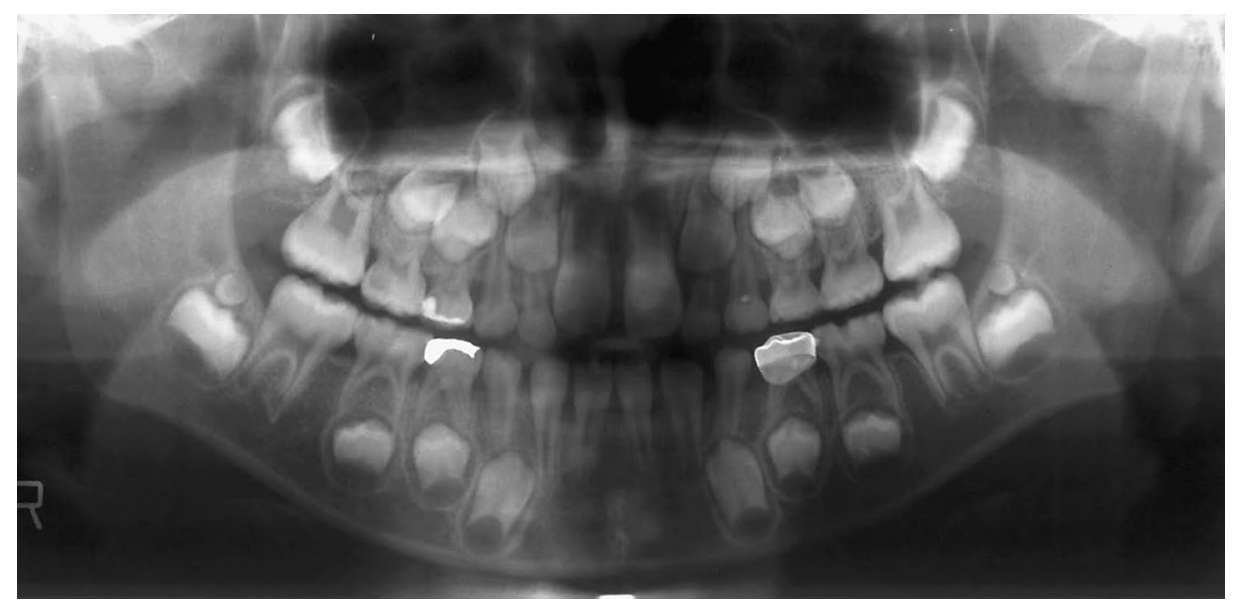

Fig. 1 Panoramic photograph of the subject at 7 years and 9 months of age shows the presence of impacted supernumerary teeth on the upper side of the bilateral mandibular second molars.

unilateral or bilateral, erupted or unerupted and in one or both jaws. Most cases of supernumerary teeth occur singly, and bilateral supernumerary teeth occur in $12-23 \%$ of the reported cases $^{9,10)}$. With respect to the molar region, in a study by Grimanis et al., $23.9 \%$ of supernumerary molars were found bilaterally ${ }^{9}$.

The present report describes a rare case of bilateral impacted supernumerary teeth in the region of the second molar buds in the mandible.

To the best of our knowledge, this is the only case report of eruption guidance for eruption disturbances of the bilateral second molars caused by supernumerary teeth.

\section{Case Report}

A 7-year, 9-month-old Japanese boy was referred to our Pediatric Dental Clinic at Niigata University Dental Hospital by his family dentist due to radiopaque materials adjacent to the bilateral mandibular second molars found on a panoramic radiograph. There was no relevant medical or family history of dental abnormalities. On intraoral examination, the following teeth were found to be erupted:

\begin{tabular}{llllll|llllll}
6 & $\mathrm{E}$ & $\mathrm{D}$ & $\mathrm{C}$ & $\mathrm{B}$ & 1 & 1 & $\mathrm{~B}$ & $\mathrm{C}$ & $\mathrm{D}$ & $\mathrm{E}$ & 6 \\
\hline 6 & $\mathrm{E}$ & $\mathrm{D}$ & $\mathrm{C}$ & 2 & 1 & 1 & 2 & $\mathrm{C}$ & $\mathrm{D}$ & $\mathrm{E}$ & 6
\end{tabular}

Additionally, no second molars had erupted and the overlying gingiva was normal. Panoramic radiograph showed a circumscribed radiolucency containing round-shaped radiopaque material on the
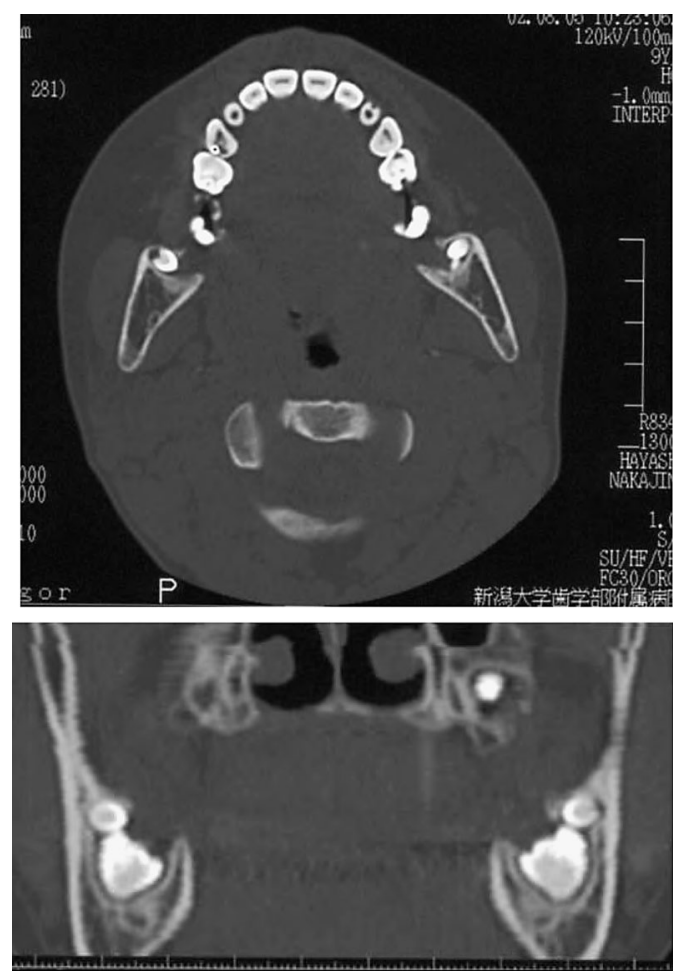

Fig. 2 CT slices showing the conical-shaped supernumerary teeth located on the upper buccal side of the unerupted lower second molars and touching the enamel surface of the distobuccal cusp of the lower second molars. The cusps of the supernumerary teeth are pointed toward the lingual side.

upper side of the bilateral mandibular second molars (Fig. 1). The crowns of the mandibular second molars were nearly fully formed and no third molar germs were detectable. The clinical diagnosis was 


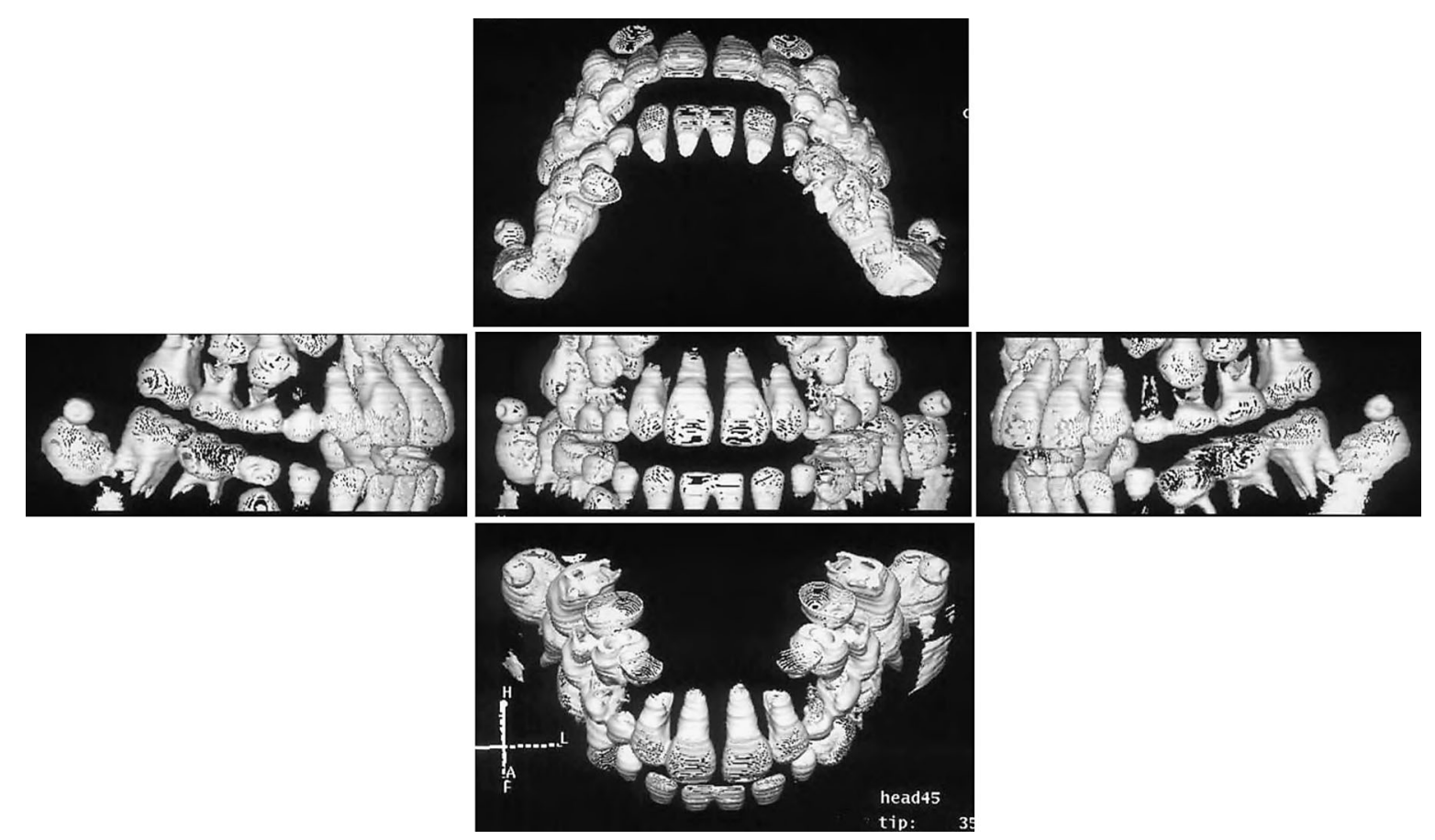

Fig. 3 A 3D reconstructed image of the teeth clearly shows the position and shape of the supernumerary teeth.

impacted supernumerary molars. We performed the periodical follow-up examinations, with taking radiographs to check the position of the supernumerary teeth and the development of the lower second molars. At the age of 9 years and 1 month, panoramic radiograph showed no positional change of the supernumerary teeth and completed crown formation of the lower second molars. Because the supernumerary molars might affect eruption of the lower second molars, computed tomography (CT) was used to examine the spatial relationships between the impacted supernumerary teeth and adjacent teeth (Fig. 2). The supernumerary teeth were located on the upper buccal side of the unerupted mandibular second molars, touching the enamel surface of the distobuccal cusp of the second molars. A 3D CT image clearly showed the location of the impacted supernumeraries (Fig. 3). The supernumeraries were conical in shape, with their cusps pointing toward the lingual side. Axial CT scan showed that the supernumerary teeth were present in the follicles of the second molars.

A panoramic radiograph at the age of 10 years and 2 months showed that the root formations of the mandibular second molars had already started. Because the supernumeraries threatened to disturb the eruption of the mandibular second molars, we

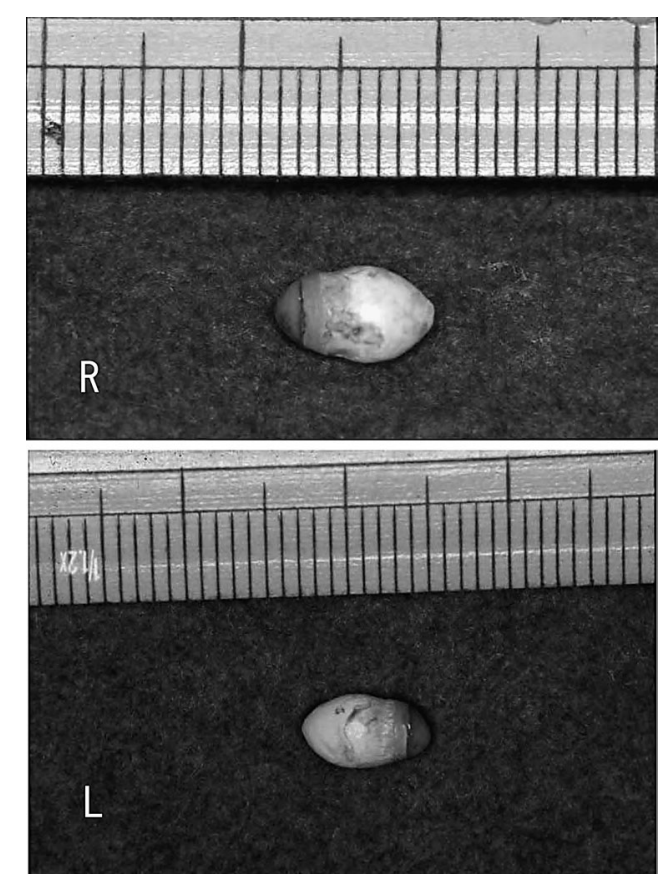

Fig. 4 Extracted supernumerary teeth with mm scale

surgically removed the supernumerary teeth.

The extracted teeth showed a conical crown structure and no root (Fig. 4). The pathologic diagnosis was supernumerary teeth. At 1 year and 1 

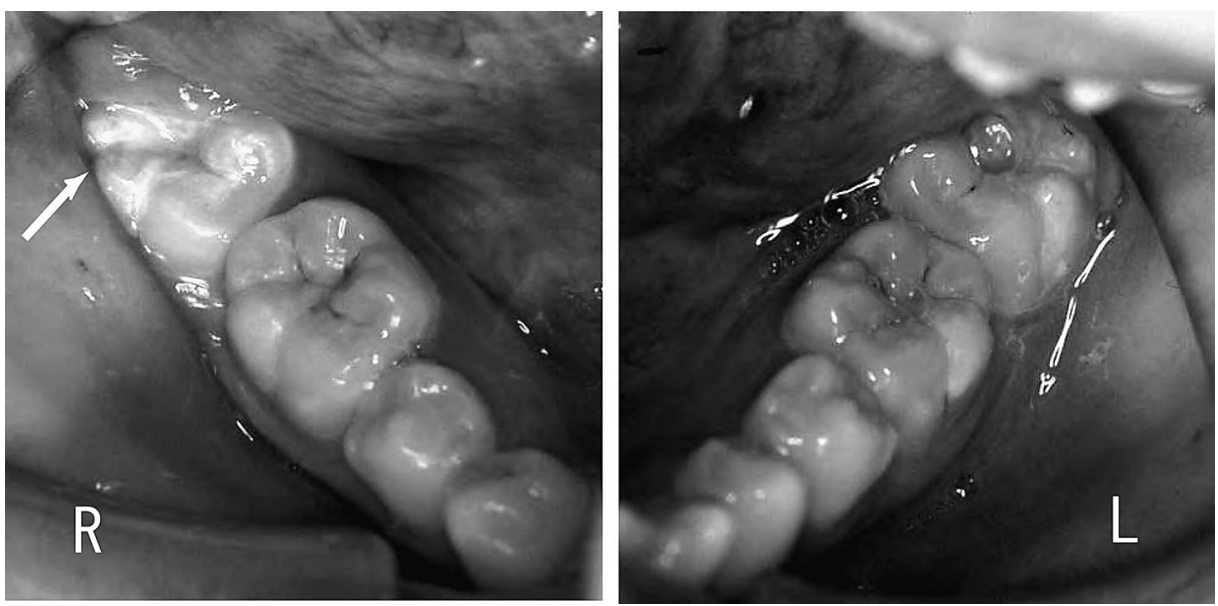

Fig. 5 Clinical photographs at the age of 12 years and 1 month. The arrow indicates slight enamel hypoplasia of the right second molar.

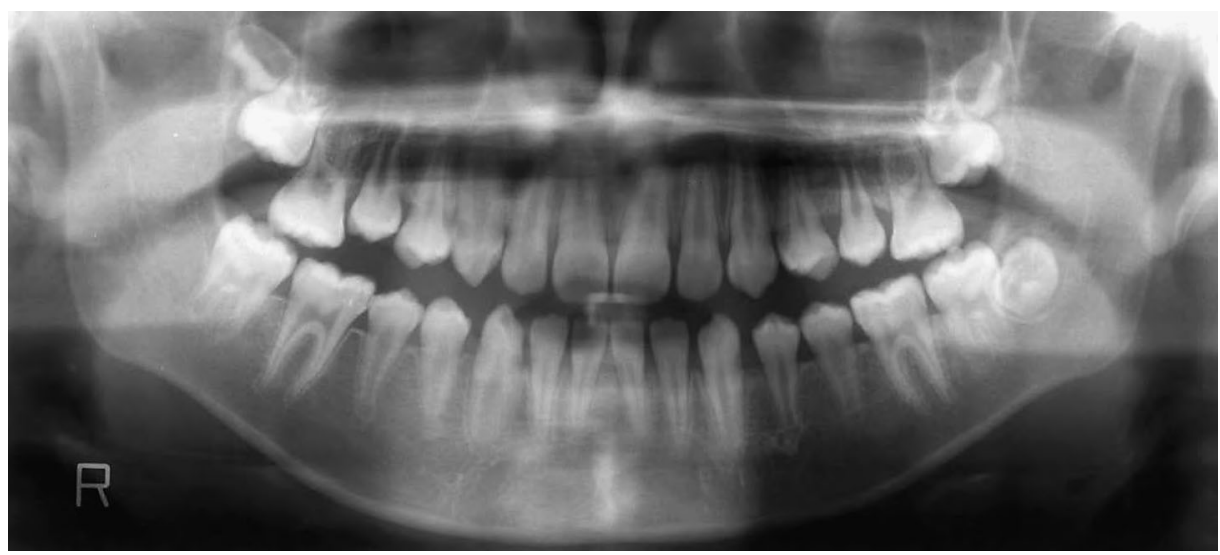

Fig. 6 Panoramic photograph taken at 12 years and 1 month shows fully erupted bilateral second molars.

month after the removal of the supernumerary teeth, the lower left second molar erupted, followed by the lower right second molar at 1 year and 7 months. At the age of 12 years and 1 month, the mandibular second molars erupted to an almost normal occlusal level (Figs. 5 and 6). The mandibular second molars were morphologically normal, while the buccal enamel surface of the right second molar showed slight enamel hypoplasia.

\section{Discussion}

The present case report describes eruption guidance for eruption disturbances of the bilateral second molars caused by supernumerary teeth in a 7-yearold patient. Although the literature indicates that maxillary supernumerary molars are not uncommon in adults, supernumerary molars in mandibles are rare. Furthermore, supernumerary molars are extremely rare in young patients, especially in the mandible. Only one case of mandibular supernumerary molars in a young patient has been previously reported ${ }^{11)}$. In that case, a 15-year-old patient had bilateral impacted supernumerary molars in the mandible, but the supernumerary teeth were located asymmetrically and did not interrupt the eruption of the adjacent teeth $^{11)}$. However, there was no mention of eruption guidance in that report.

Many hypotheses concerning the cause of supernumerary teeth have been suggested, but their occurrence has not yet been fully clarified. It has been suggested that supernumerary teeth result from atavism or reversion; however, malformed and conical-shaped teeth cannot be accounted for 
by atavism ${ }^{3)}$. In the present case, the shape of the supernumerary teeth was conical.

Aberrations during embryological formation may cause the formation of supernumerary teeth. For example, it is believed that supernumerary teeth may arise from local, independently conditioned hyperactivity of the dental lamina or remnants of the dental lamina ${ }^{12-14)}$. It is also possible that supernumerary teeth may result from the division of a developing tooth bud (dichotomy); there are a number of factors that might split a normal tooth germ and give rise to the development of multiple individual teeth ${ }^{9,15}$.

Heredity is an important factor in the occurrence of supernumerary teeth. Supernumerary teeth occasionally occur within the same family ${ }^{16-19}$. Some inheritance patterns have been suggested, such as an autosomal dominant trait without penetrance in some generations ${ }^{17)}$, or sex-linked inheritance ${ }^{20)}$. Most cases of supernumerary teeth, however, do not follow a Mendelian inheritance pattern, suggesting that the occurrence of supernumerary teeth is a type of disorder that follows a pattern of multifactorial inheritance ${ }^{19)}$. In the present case, the cause was determined to be not only local environmental factors but also genetic factors because the supernumerary teeth were present bilaterally.

Supernumerary teeth in the molar region are known as paramolars if they are located buccal to the regular molars ${ }^{21)}$. Bolk ${ }^{8)}$ suggested that accessory buccal cusps (paramolar tubercles) and paramolars are homologous and that excess development of paramolar tubercles would lead to the development of supernumerary teeth. Although the etiology of paramolar tubercles is not yet known, it has been suggested to be genetically dependent. Even though it is rare for paramolar tubercles to occur bilaterally on the distobuccal side of the molar, this hypothesis could apply to the present case because the supernumerary teeth existed in the follicle of the second molars and their developmental stage was similar to that of the second molars.

Supernumerary teeth might cause dental abnormalities such as the delayed eruption or impaction of permanent teeth, malposition of the supernumerary teeth, and displacement of adjacent teeth. Such eruption disturbances can be prevented by early diagnosis and appropriate treatment. To determine an appropriate treatment plan for supernumerary teeth, it is important to evaluate their exact positions and the moment at which the teeth might cause various disturbances. In the present case, the supernumerary teeth were identified at an early stage of development. We were therefore able to determine that the supernumerary teeth might disturb the eruption of the second molars because CT imaging made it possible to accurately see the teeth in three dimensions and to visualize their position relative to the second molars. Reconstructed 3D images from spiral CT devices are helpful in understanding the position and anatomy of supernumerary teeth. In the present case, we were able to remove the supernumerary teeth after crown formation of the second molars, allowing the second molars to erupt at a normal age and to align correctly within the dentition. In regard to eruption disturbance caused by supernumerary tooth, there have been several reports that the tooth erupts after the removal of supernumerary teeth ${ }^{22,23)}$. However these reports concerned the maxillary incisor, and there have been no reports of the eruption disturbances of the bilateral second molars caused by supernumerary teeth. At the extraction of the embedded supernumerary tooth, we may damage an adjacent permanent tooth germ ${ }^{24,25)}$. As a tooth is going to erupt after the formation of dental root begins ${ }^{26)}$, abnormal position and/or abnormal form can easily occur if the supernumerary tooth is left in place for a long period.

In the present case, we waited for completion of crown formation in the second molars, and the supernumerary teeth were carefully removed after root formation of the second molars began.

\section{References}

1) Noda, T., Takagi, M., Hayashi-Sakai, S. and Taguchi, Y.: Eruption disturbances in Japanese children and adolescents. Pediatr Dent 16: 50-56, 2006.

2) Gorlin, R.J. and Goldman, H.M.: Supernumerary teeth: report of three cases and review of the literature. In: Thoma's Oral Pathology. 6th ed. Vol. 1. CV Mosby Co., St. Louis, 1970, pp.112-123.

3) Stafne, E.C.: Supernumerary teeth. Dent Cosmos 74: 653-659, 1932.

4) Primosch, R.: Anterior supernumerary teeth assessment and surgical intervention in children. Pediatr Dent 3: 204-215, 1981.

5) Stellzig, A., Basdra, E.K. and Komposch, G.: Mesiodentes: Incidence, morphology, etiology. J Orofac Orthop 58: 144-153, 1997.

6) McKibben, D.R. and Brearly, L.J.: Radiographic determination of the prevalence of selected dental anomalies in children. J Dent Child 28: 390-398, 1971.

7) Luten, R.J.: The prevalence of supernumerary teeth 
in primary and mixed dentitions. J Dent Child 34: 346-353, 1967.

8) Bolk, L.: Supernumerary teeth in the molar region in man. Dent Cosmos 56: 154-167, 1914.

9) Grimanis, G.A., Kyriakides, A.T. and Spyropoulos, N.D.: A survey on supernumerary molars. Quintessence Int 22: 989-995, 1991.

10) Rajab, L.D. and Hamdan, M.A.: Supernumerary teeth: review of the literature and a survey of 152 cases. Int J Paediatr Dent 12: 244-254, 2002.

11) Timocin, N., Yalcin, S., Ozgen, M. and Tanyeri, H.: Supernumerary molars and paramolars. J Nihon Univ Sch Dent 36: 145-150, 1994.

12) Liu, J.F.: Characteristics of premaxillary supernumerary teeth: a survey of 112 cases. J Dent Child 62: 262-265, 1995.

13) Fisher, S.E.: Maxillary sixth molars. Br Dent J 152: 356, 1982.

14) Gallas, M.M. and Garcia, A.: Retention of permanent incisors by mesiodens: a family affair. Br Dent $J \mathbf{1 8 8}$ : 63-64, 2000.

15) Hattab, F.N., Yassin, O.M. and Rawashdeh, M.A.: Supernumerary teeth: report of three cases and review of the literature. J Dent Child 61: 382-393, 1994.

16) Marya, C.M. and Kumar, B.R.: Familial occurrence of mesiodentes with unusual findings: case reports. Quintessence Int 29: 49-51, 1998.

17) Sedano, H.O. and Gorlin, R.J.: Familial occurrence of mesiodens. Oral Surg Oral Med Oral Pathol 27: 360-361, 1969.
18) Foley, M.F. and Del Rio, C.E.: Supernumerary teeth. Report of a case. Oral Surg Oral Med Oral Pathol 30: 60-63, 1970.

19) Brook, A.H.: A unifying aetiological explanation for anomalies of human tooth number and size. Arch Oral Biol 29: 373-378, 1984.

20) Bruning, L.J., Dunlap, L. and Mergele, M.E.: Report of supernumerary teeth in Houston Texas school children. J Dent Child 24: 98-105, 1957.

21) Omur, A.K.: Paramolar structures of the upper dentition. J Dent Res 41: 75-83, 1962.

22) Gregg, T.A. and Kinirons, M.J.: The effect of the position and orientation of unerupted premaxillary supernumerary teeth on eruption and displacement of permanent incisors. Int J Paediatr Dent 1: 3-7, 1991.

23) Betts, A. and Camilleri, G.E.: A review of 47 cases of unerupted maxillary incisors. Int J Paediatr Dent 9: 285-292, 1999.

24) Nozaka, K., Sasaki, K., Sasaki, M., Moriguti, O. and Amari, E.: Effect to the adjacent central incisors of impacted supernumerary upper central incisors. Jpn J Ped Dent 18: 502-512, 1980. (in Japanese)

25) Hasegawa, K., Nakazawa, N., Tonogi, N. and Machida, Y.: Longitudinal observation on upper supernumerary mesiodens. Jpn J Ped Dent 29: 428-438, 1991. (in Japanese)

26) Shumaker, D.B. and El Hadary, M.S.: Roentgenographic study of eruption. J Am Dent Assoc 61: 535$541,1960$. 